\title{
The interaction of social class and type of reinforcement in discrimination learning'
}

MARTIN A. SAFER ${ }^{2}$ AND L. BERELL KORNREICH, DEPARTMENT OF PSYCHOLOGY, UNIVERSITY OF WISCONSINMILWAUKEE, Milwaukee, Wisc. 53201

Two experiments attempted to replicate the Terrell, Durkin, \& Wiese (1959) finding that iower class children learn a discrimination faster when given "concrete" reinforcements while middle class children learn faster when given "abstract" reinforcements. The two experiments yielded contradictory results, one supporting and one rejecting the Terrell et al hypothesis. The need for further research using a different experimental task is discussed.

Terrell, Durkin, \& Wiese (1959) reported an interaction between social class and the nature of the incentive in a discrimination learning problem. Specifically they found that lower class children who were reinforced by candy and a light flash for correct responses learned faster than middle class children who received candy and light or lower class children who received just light. Conversely, middle class children who received just light as a reinforcer learned faster than lower class children who received light or middle class children who received both light and candy. Hence, lower class children learned faster when given "concrete," candy reinforcers while middle class children learned faster with "abstract," light reinforcers. Zigler \& Kanzer (1962) reported that abstract reinforcers were more effective social reinforcers with middle class children; however, Rosenhan \& Greenwald (1965) failed to replicate their results. The present experiments attempt to replicate and extend the Terrell et al (1959) experiment.

\section{EXPERIMENT 1}

Subjects. The Ss were 53 children from the UWM Campus School who ranged in age from 65 to 138 months. Ss were rated on social class according to their father's ranking on the Warner occupation scale (Warner, Meeker, \& Eells, 1949, p. 140). Three groups of children were formed: those whose father had Occupation Level $1(\mathrm{~N}=19)$, Levels 2 and $3(\mathrm{~N}=21)$, and Levels 4 and $5(\mathrm{~N}=13)$.

Apparatus. The apparatus was a large, black board with a light in its center and two telegraph keys, one attached to the left side of the board and one to the right side. The stimuli were pairs of similar, geometric figures (cubes, pyramids, cylinders); the smaller had base area of $4 \mathrm{sq}$ in., the larger was $8 \mathrm{sq}$ in.

Procedure. The Ss within the three social class groups were randomly assigned either to the light (L) or light and candy $(\mathrm{L}+\mathrm{C})$ treatment. The Ss were run individually by two Es who did not know the social class of $S$. The general procedure was as follows: $E_{2}$ knew what choice $S$ had made. The order of presentation was random except that no pair was presented more than twice in succession and the larger figure was not on one side more than three times in a row. When $S$ chose the larger figure, $E_{2}$ delivered the reinforcement. Candy reinforcement, M \& Ms, was delivered through a chute in to a cup about 6 in. to the S's left; light reinforcement was a $2 \mathrm{sec}$ flash of the light in the center of the board. The $S$ was told he could eat the $M \& M$ s immediately or save them. The instructions and procedure were similar to Terrell et al, except that in the present experiment, there was a training limit of $\mathbf{4 0}$ trials; Terrell et al reported no upper limit. The learning criterion was nine correct out of 10 consecutive trials.

Results and Discussion. The Ss in the $L$ group took significantly less trials than $\mathrm{L}+\mathrm{C}$ (Mann-Whitney $\mathrm{U}$ test, $\mathrm{Z}=2.92, \mathrm{p}<.005$ ). There were no differences due to the social class of the children in either the $\mathrm{L}$ or $\mathrm{L}+\mathrm{C}$ groups. In both the $\mathrm{L}$ and $\mathrm{L}+\mathrm{C}$ groups the number of trials to criterion was negatively correlated with age ( $r$
$=-.52, \mathrm{p}<.01 ; \mathrm{r}=-.40, \mathrm{p}<.05)$, and with mental age $(\mathrm{r}=-.65, \mathrm{p}$ $<.01 ; \mathrm{r}=-.34, \mathrm{p}<.20$ ). IQ was not significantly correlated with trials to criterion for either group. Thus older children learned in fewer trials in this study, whereas Terrell et al found no effect due to age. In general the Terrell et al hypothesis was supported, since even Occupation Levels 4 and 5 are lower middle class. It would be predicted by the Terrell et al finding that the $S s$ in Experiment 1 should learn faster in the $L$, rather than the $L+C$, group.

\section{EXPERIMENT 2}

The apparatus and procedure were identical to Experiment 1. Ss were 96 children from St. Leo's School who ranged in age from 76 to 126 months. Ss were designated as middle class if their father had an occuaption ranking of 1-5 (primarily 4 and 5) and had completed high school, and as lower class if their father had a rating of 5-7 and had not completed high school. There were three treatment groups: $L, L+C$, and a group which received just candy reinforcement (C). Ss were matched according to age and then were assigned to one of six groups (two social classes by three reinforcement conditions).

Results and Discussion. There were no significant differences between the two social groups, no significant differences due to the treatments, and no significant correlation between S's age and number of trials to criterion. The results failed to replicate either the social class finding of Terrell et al, or the age finding from the first experiment. In both experiments the trials to criterion were higher than those reported by Terrell et al. In Experiment $128 \%$ and in Experiment $242 \%$ of the Ss did not learn the discrimination in 40 trials. In fact, since one-trial learners began the experiment by preferring the correct stimulus, it is questionable whether they learned anything during the experiment. Only $43 \%$ of the $\mathrm{Ss}$ in Experiment 2 actually learned, that is reached criterion between trials 2-29. Significantly more Ss in Experiment 1 (who were all middle class) than in Experiment 2 "learned" by this criterion $\left(x^{2}=9.75, \mathrm{df}=2, \mathrm{p}<.01\right)$.

The task used by Terrell et al and in the present experiments seems quite insensitive to learning effects, especially for the lower class children. In order to test properly the interesting Terrell et al hypothesis that an interaction exists between type of reinforcement and social class in learning a discrimination, a task should be used which requires learning before the criterion can be met. Yet this task should not be so difficult that a large proportion of the Ss fail to meet the criterion.

\section{REFERENCES}

ROSENHAN, D., \& GREENWALD, J. A. The effects of age, sex, and socioeconomic class on responsiveness to two classes of verbal reinforcement. J. Pers., 1965, 33, 108-121.

TERRELL, G., DURKIN, K., \& WIESLEY, M. Social class and the nature of incentive in discrimination learning. J. abnorm soc. Psychol., 1959, 59, 270-272.

WARNER, W., MEEKER, M., \& EELLS, K. Social class in America. Chicago: Science Research Associates, 1949.

ZIGLER, E., \& KANZER, P. The effectiveness of two classes of verbal reinforcers on the performance of middle- and lower-class children. J. Pers., $1962,30,157-163$.

\section{NOTES}

1. The research was facilitated by an NSF undergraduate research grant No. GY-2639. The authors wish to thank the research staff of the UWM Campus Elementary School, Sister Eustace of St. Leo's Parish Elementary School, and Dena Schiewitz who helped run the Ss.

2. Now at the University of Wisconsin-Madison. 